\title{
Use of Ames SG10 Urine Dipstick for diagnosis of abdominal pain in the accident and emergency department
}

\author{
R. MCGLONE ${ }^{1}$, M. LAMBERT ${ }^{1}, M$. CLANCY ${ }^{2} \&$ \\ P. M. HAWKEY
}

${ }^{1}$ Accident and Emergency Department, Leeds General Infirmary, Leeds; ${ }^{2}$ Accident and $\stackrel{\vec{\omega}}{\stackrel{\omega}{\omega}}$

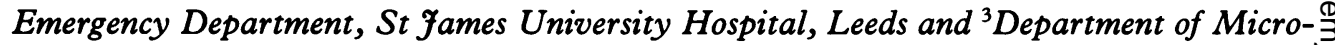
biology, University of Leeds, Leeds

\section{SUMMARY}

In a prospective study of 1112 patients presenting to the Accident and Emergency $\vec{\bullet}$ Department with abdominal pain; the SG10 Ames Urine Dipsticks were shown to beg \& valuable screening test for the detection of infected urine. Introducing this technique would reduce by at least $37 \%$ the number of urgent requests for microscopy of mi stream urines (MSUs). Dipstick testing however was not a reliable screening test for microscopic haematuria.

\section{INTRODUCTION}

It has been policy at the two main teaching hospitals in Leeds to send for urgent 3 microscopy all urine samples from patients presenting with abdominal pain. A previous study has suggested that the MSU is of more value than a FBC (de Dombal et al., 1989). However, to perform urgent microscopy 'out of normal hours' on all such patients has financial implications. Both sites together on average order 14 such tests a day, each one attracting a call out fee for the Medical Laboratory Scientific Officer. Also the patient may have to wait longer in the Accident and Emergency Department until the MSU result is ready, and because of this potential delay the Accident and Emergency nurse $N$ may order an MSU even before a doctor has seen the patient, 'to save time'.

A survey of 669 MSUs in the Accident and Emergency Department showed that $29 \%$ appeared totally irrelevant to the patient's management (de Dombal et al., 1989).

Correspondence: Dr R. McGlone, Accident and Emergency Department, Leeds General Infirmary, Great George $\stackrel{\mathscr{R}}{?-}$ Street, Leeds LS1 3EX, England. 
To reduce the usage of urgent microscopy, urine sticks could be usefully used to screen out the normal urines. However, this would be possible only if the number of false negatives were minimal. Several studies have shown this to be the case when the test is carried out by laboratory staff (Loo et al., 1984; Bank et al., 1987; Boreland et al., 1986; Brown, 1988). Indeed, the predictive value for a negative growth was shown to be greater with stick testing (Leucocyte esterase and/or nitrite), $94.9 \%$ compared to microscopy $92 \%$ (Loo et al., 1984). The precision can be further improved, if photometry is used to read the strip-test (Boreland et al., 1986).

No similar study has been done in the Accident and Emergency Department where there would be two important differences: urines would be freshly voided and nursing staff would be performing the test.

In view of the potential savings in time and cost, it was decided to assess the Ames SG10 dipstick at the Accident and Emergency Departments of the Leeds General Infirmary (LGI) and St James's University Hospital.

\section{MATERIALS AND METHODS}

One thousand one hundred and twelve patients, presenting to the Leeds Accident and Emergency Departments with abdominal pain, had their urine tested with the Ames SG10 stick, which assesses 10 parameters, including protein, blood, nitrite and leucocyte esterase.

Colour changes were assessed visually using the colour chart provided. Nursing staff performing the test varied in seniority from student nurse to sister/charge nurse, all of whom had been circularized with a protocol.

The results were recorded on a printed form, along with patient details. The reverse side of the form was used for recording the microscopy results and growth when the microbiology report form was returned to the department several days later.

The urines were regarded as negative to stick testing if the four parameters, blood, protein, nitrite and leucocyte esterase were negative.

Standard methods were used to perform urine microscopy. At St James's Hospital a method using an inverted microscope to count cells sedimented from a $60 \mu \mathrm{l}$ sample of urine in a microlitre tray was used (Lewis, 1989). The method used at the Leeds General Infirmary was slightly different, $100 \mu$ lof urine was placed on a slide, a cover slip placed on top and the width of the cover slip examined in one pass from side to side using a X40 objective and X10 eye-piece counting the cells present (Thomas, 1971). In both laboratories a white cell count in excess of $10 \mathrm{cells} / \mathrm{cu} \mathrm{mm}$ was regarded as representing significant pyuria (Lewis, 1989).

\section{STATISTICAL TERMS}

The sensitivity, specificity and predictive values for positive and negative strip tests were calculated as below. 
Sensitivity $\%=\frac{\text { true positive }}{\text { true positive }+ \text { false negative }} \times 100$

Specificity $\%=\frac{\text { true negative }}{\text { true negative }+ \text { false positive }} \times 100$

Predictive value for $=\frac{\text { true positive }}{\text { true positive }+ \text { false positive }} \times 100$ positive result $\%$

Predictive value for $=\frac{\text { true negative }}{\text { true negative }+ \text { false negative }} \times 100$ negative result $\%$

Specimens were cultured using a standard disposable $2 \mu$ l loop on CLED agar (Oxoidw Ltd., Basingstoke, England). If pyuria and no growth was found, urine was plated on blood agar and incubated anaerobically and aerobically at $37^{\circ} \mathrm{C}$ for up to $48 \mathrm{~h}$. A positive culture was defined as one that had $\geqslant 10^{5}$ colony forming units $/ \mathrm{ml}(\mathrm{CFU} / \mathrm{ml})$ in eitherpure culture or mixed culture.

\section{RESULTS}

A total of 1112 urine samples were assessed, of which only 1080 samples could ha\&e complete analysis performed on them, as 32 had incomplete data on the form. Predictably $71.4 \%$ of specimens were from female patients.

For the purposes of analysis growth was defined as bacteriuria $\geqslant 10^{5} \mathrm{CFU} / \mathrm{m}$ including mixed growth. Growth was present in $10.4 \%$ of MSU specimens (LGI $11.8 \%$; St James's: 8.9\%). Appearance can be an indicator of bacteriuria, but most. samples were clear and very few turbid (4\%). The results of other stick tests are showng in Table 1.

Specific gravity peaked at 1.010 but skewed towards concentrated urine. The urine

Table 1 Table showing results of testing 1080 patients' urine samples with the Ames SG10 urine dipstick

\begin{tabular}{lrr}
\hline Test & \multicolumn{2}{c}{$\%$ Positive } \\
\hline Glucose & $4 \cdot 0$ & \\
Ketone & $23 \cdot 0$ & \\
Protein ('trace') & $34 \cdot 1$ & $(16 \cdot 5)$ \\
Blood ('trace') & $40 \cdot 8$ & $(15 \cdot 6)$ \\
Leucocyte ('trace') & $28 \cdot 3$ & $(8 \cdot 8)$ \\
Nitrite & $5 \cdot 8$ & \\
Bilirubin & $7 \cdot 3$ & \\
Urobilirubin & $2 \cdot 5$ & \\
pH $>7$ & $14 \cdot 7$ & \\
pH $\geqslant 8$ & $8 \cdot 8$ & \\
\hline
\end{tabular}


was orange/yellow in appearance in $16 \%$ of cases which could account for a high false positive rate for bilirubin. Only in $8.6 \%$ of the infected urines was the $\mathrm{pH}>7$.

The effects of the different parameters of the stick-test versus growth were expressed individually and in combination, see Table 2 . The results for microscopy (WBC $\geqslant 10$ per $\mathrm{mm}^{3}$ ) versus growth are shown in Table 3. Comparison of stick testing for blood versus microscopic haematuria is shown in Table 4.

If cultures with mixed growth and contaminated culture reports are excluded from analysis, then the number of false negatives for the combined four stick tests versus growth is reduced from 13 to 5 . Two of these five patients complained of dysuria and the remaining three specimens had less than $10 \mathrm{WBC}$ per $\mathrm{mm}^{3}$ on microscopy. Sensitivity increases to $94.8 \%$, specificity is not significantly affected $(39.9 \%)$ and the predictive value for a negative result is $\mathbf{9 8 . 7 \%}$. If only this 'significant growth' is considered then

Table 2 Table showing statistical analysis of results of testing 1080 patients' urine samples with Ames SG10 strip test. Four separate tests are analysed both separately and in various combinations versus culture.

\begin{tabular}{|c|c|c|c|c|}
\hline Parameters & Sensitivity & Specificity & $\begin{array}{l}\text { Predictive value } \\
\text { Negative result }\end{array}$ & $\begin{array}{l}\text { Predictive value } \\
\text { Positive result }\end{array}$ \\
\hline Nitrite $(\mathbf{N})$ & $39 \cdot 2 \%$ & $98 \cdot 6 \%$ & $92 \cdot 6 \%$ & $77 \cdot 7 \%$ \\
\hline Blood (B) & $66.9 \%$ & $62 \cdot 3 \%$ & $93.5 \%$ & $18.9 \%$ \\
\hline Protein (P) & $57.9 \%$ & $68.9 \%$ & $92.6 \%$ & $19 \cdot 5 \%$ \\
\hline \multicolumn{5}{|l|}{ Leucocyte (L) } \\
\hline esterase & $66 \cdot 1 \%$ & $76 \cdot 5 \%$ & $94.5 \%$ & $26 \cdot 8 \%$ \\
\hline N.B. & $80 \cdot 6 \%$ & $62 \cdot 0 \%$ & $96 \cdot 1 \%$ & $21 \cdot 6 \%$ \\
\hline N.L. & $72 \cdot 6 \%$ & $76 \cdot 5 \%$ & $95 \cdot 6 \%$ & $28 \cdot 6 \%$ \\
\hline N.B.L. & $87 \cdot 9 \%$ & $49 \cdot 8 \%$ & $96.9 \%$ & $18 \cdot 5 \%$ \\
\hline N.P.L. & $83 \cdot 1 \%$ & $55 \cdot 3 \%$ & $96 \cdot 2 \%$ & $19 \cdot 2 \%$ \\
\hline N.B.P.L. & $89.5 \%$ & $40 \cdot 1 \%$ & $96 \cdot 4 \%$ & $16 \cdot 2 \%$ \\
\hline N.B.P. & $85.5 \%$ & $48 \cdot 5 \%$ & $96 \cdot 3 \%$ & $17 \cdot 7 \%$ \\
\hline $\begin{array}{l}\text { N.B.P. } \\
\text { (Trace protein } \\
\text { negative) }\end{array}$ & $82.3 \%$ & $56 \cdot 6 \%$ & $96 \cdot 1 \%$ & $19 \cdot 7 \%$ \\
\hline
\end{tabular}

Table 3 Analysis of the results of microscopy versus culture as a predictor of urinary tract infection

\begin{tabular}{lcc}
\hline & \multicolumn{2}{c}{ WBCs per high field on microscopy } \\
& $\leqslant 10$ & $>10$ \\
\hline No growth & 863 & 95 \\
Growth & 36 & 86 \\
\hline & & $70 \cdot 5 \%$ \\
& Sensitivity & $90 \cdot 1 \%$ \\
& Specificity & $47.5 \%$ \\
& Pred. value positive & $96 \cdot 0 \%$ \\
\hline
\end{tabular}


Table 4 An analysis of strip testing versus microscopy as a predictor of haematuria

\begin{tabular}{|c|c|c|c|}
\hline & & \multicolumn{2}{|c|}{ Microscopy } \\
\hline & & Nil seen & Red cells present \\
\hline Strip test + ve & & 260 & 182 \\
\hline \multirow[t]{5}{*}{ Strip test - ve } & & 591 & 47 \\
\hline & Sensitivity & & $79.5 \%$ \\
\hline & Specificity & & $69 \cdot 4 \%$ \\
\hline & Pred. value + ve & & $41 \cdot 2 \%$ \\
\hline & Pred. value - ve & & $92 \cdot 6 \%$ \\
\hline
\end{tabular}

the number of false negative results for microscopy decrease from 36 to 20 cases with asensitivity of $81 \cdot 1 \%$ and a specificity of $90 \cdot 2 \%$. In all, $26 \%$ of urines with growth were considered not to be clinically significant, probably reflecting the difficulty in obtaining clean mid-stream urine specimens in the Accident and Emergency Department.

\section{DISCUSSION}

The study successfully showed that strip testing can be used to identify normal uriâed samples and therefore exclude them from urgent microscopy and plating.

If the results of stick testing for proteinuria are omitted, so testing only blood, nitriteå and leucocyte esterase, then there is a slight reduction in sensitivity but an increase in $\frac{\mathscr{Q}}{\varnothing}$ specificity. The number of false negatives is increased from 13 to 14 , the additional one $\overrightarrow{\overrightarrow{0}}$ being a significant infection. If the latter was used as a screening test then there would 3 be a $45 \%$ reduction in MSUs requested as opposed to $37 \%$ if all 4 parameters were? used. Strip testing compares favourably with microscopy which showed a higher false negative rate and a significant false positive rate.

Lowe (1985) compared a dipstick screen using blood, protein, nitrite with and: without leucocyte esterase. When the leucocyte esterase test was used the specificity of the screen was reduced from $60.8 \%$ to $37.7 \%$-the test being frequently positive in females from whom the urines were contaminated by vaginal secretions. The author did not recommend the inclusion of leucocyte esterase in a screening test, however, the predictive value for a negative result was only $88.8 \%$ compared to $96.4 \%$ in our studyo using the same four parameters.

In a study by de Dombal et al. (1989) of $669 \mathrm{MSUs}$ from patients with acute ${ }^{N}$ abdominal pain, the result wrongly suggested a diagnosis in $4.8 \%$ of cases. Junior doctors need to appreciate the high false positive rate particularly in female patients and the significant false negative rate when using microscopy as a predictor of urinary tract infection. One particular patient whose urine was positive to nitrite with no cells seen on $\bar{\Phi}_{\bar{\Phi}}$ microscopy, subsequently died later that day due to an $E$. coli septicaemia secondary to a $\stackrel{\oplus}{+}$ UTI. The significant false negative rate may be secondary to a combination of observer $\vec{T}$ 
error and cell lysis especially in urine of low specific gravity. Microscopy is by no means the gold standard for diagnosis of UTI.

Six patients with nitrite positive strip tests had a mixed growth on culture and were discounted as not having a 'significant infection'. However, all these MSUs had WBC $\geqslant 10$ per $\mathrm{mm}^{3}$ on microscopy and in view of the recognized high specificity of the nitrite for bacteriuria such culture results should be scrutinized and perhaps a further specimen requested.

Urgent microscopy is also requested in cases of suspected renal colic. In this respect stick testing was disappointing in that it failed to detect red blood cells seen on microscopy in 47 cases. In only 7 of these cases was the result greater than $20 \mathrm{RBC}$ per $\mathrm{mm}^{3}$ which is the definitive sensitivity threshold for the strip test (Ames Division, Miles Laboratories-unpublished data). This result would most probably be improved if photometry was used. The question not answered by the trial is how many cases of microscopic haematuria were missed due to cell lysis.

Not all hospitals have the facilities to perform urgent microscopy on urine and in this present financial climate this situation may become the norm unless departments are more selective in its use. The addition of a photometer to read the dipstick would undoubtedly improve the reliability of the test. Boreland (1986) showed that comparing nitrite, blood and protein versus culture, the predictive value for a negative result could be increased from $96.3 \%$ to $99.1 \%$ by the use of a photometer. However, our study shows that visually read strips are sufficiently reliable and could produce savings in both time and cost.

\section{ACKNOWLEDGEMENT}

Our thanks to Mr R. Newall of Ames Division.

\section{REFERENCES}

Bank C. M., Codrington J. F., VanDieijen-Visser M. P. \& Brombacker P. J. (1987) Screening urine specimen populations for normality, using different dipsticks. Fournal of Clinical Chemistry and Clinical Biochemistry 25, 299-307.

Boreland P. C. \& Stoker M. (1986) Dipstick analysis for screening of paediatric urine. fournal of Clinical Pathology 39, 1360-2.

Brown H. (1988) Chemical Screening of 'routine' urines to improve efficiency, without lowering standards. Medical Laboratory Sciences 45, 304-7.

De Dombal F. T., Illingworth R. N. \& Dallos V. (1989) Protocols for investigation of patients with acute abdominal pain. In preparation.

Lewis D. A. (1989) In: Medical Bacteriology-a Practical Approach. Eds. Hawkey P. M. and Lewis D. A., IRL Press, Oxford, p. 7.

Loo S., Scottolini A. G., Luangphinith S., Adam A. L., Jacobs L. D. \& Maniani A. J. (1984) Urine screening strategy, employing dipstick analysis and selective culture: an evaluation. American fournal of Clinical Pathology 81, 634-42.

Lowe P. (1985) Chemical screening and prediction of bacteriuria-a new approach. Medical Laboratory Sciences 42, 28-33.

Thomas M. (1971) A rapid slide method for urine cell counts. Medical Laboratory Technology 28, 38-9. 